\title{
Sequential masking during eye fixations in reading
}

\author{
MARIA L. SLOWIACZEK \\ University of Texas at Austin, Austin, Texas \\ and \\ KEITH RAYNER \\ University of Massachusetts, Amherst, Massachusetts
}

\begin{abstract}
Letters in the center of vision were masked during readers' eye fixations. Although Experiment 1 suggested that letters are processed sequentially, Experiment 2 demonstrated that the results were due to the fact that letters fixated on fixation $n$ receive preliminary processing on fixation $n-1$ when they are in parafoveal vision. When no parafoveal information was available, the results indicated that letters are processed in parallel.
\end{abstract}

Rayner, Inhoff, Morrison, Slowiaczek, and Bertera (1981) found that if text was available for $50 \mathrm{msec}$ prior to the onset of a mask, reading was almost as good as when no mask was presented. They masked the letters in the center of vision at the outset of each fixation and showed that while there was an advantage to having the text available for the full fixation, the interference caused by a mask presented after $50 \mathrm{msec}$ was quite small. They concluded that most of the visual information needed to read is available by $50 \mathrm{msec}$ into the fixation.

The experiments reported here were an extension of those reported by Rayner et al. (1981) and dealt with the extent to which letters are processed serially in a fixation in reading. If there is a sequential scan during eye fixations, it would have to be very rapid, in the range of $10 \mathrm{msec}$ per letter (Geyer, 1970). In the present experiments, subjects were asked to read as letters were masked sequentially during each fixation.

\section{EXPERIMENT 1}

\section{Method}

Subjects. Nine volunteers with normal uncorrected vision were paid to participate as subjects.

Procedure. When a subject arrived for the experiment, a bite bar was prepared to eliminate head movements, and the eyetracking system was calibrated. Subjects were told to read sentences displayed on a cathode-ray tube (CRT) and to press a key when they were finished. They were told that a mask would obstruct part of the sentence shortly after each saccade. When the key was pressed, the sentence was erased from the screen and the subject reported the sentence.

Materials and Apparatus. The sentences (5-10 words long) were displayed on a Hewlett-Packard 1300 CRT, which has a P-31 phosphor with the characteristic that removing a character results in a drop to $1 \%$ of maximum brightness in $0.25 \mathrm{msec}$. The sentences were in lower-

This research was supported by Grant BNS- 8609336 from the National Science Foundation. Requests for reprints should be sent to Keith Rayner, Psychology Department, University of Massachusetts, Amherst, MA 01003. case letters, and three letters equaled $1^{\circ}$ of visual angle. The visual mask used in the experiments consisted of an interlaced square-wave grating. The mask replaced both the letters and the spaces between words.

Eye movements were recorded with a Stanford Research Institute DualPurkinje Eyetracker, which has a resolution of $10^{\prime}$ of arc. The eyetracker and CRT were interfaced to a Hewlett-Packard 2100 computer that controlled the experiment and kept a record of the duration and location of each fixation. The analog signal of the eye position was sampled every millisecond by the computer through an analog-to-digital converter. Over each $4 \mathrm{msec}$, the position of the eye was compared to the position $4 \mathrm{msec}$ earlier to determine if the eye was in a saccade or a fixation. Eye movements were monitored from the subject's right eye, $46 \mathrm{~cm}$ from the CRT, and viewing was binocular.

Design. The sentences were displayed with three masking regions: (1) a 7-character mask, (2) a 15-character mask, and (3) no mask. The masks were symmetric around the fixated character, so that for the 7character mask conditions, the fixated characters plus 3 characters to the left and to the right were replaced by the mask. Once the mask was presented, the characters remained masked until the subject made an eye movement to fixate elsewhere in the text. There were two types of masks: simultaneous masks and sequential masks. The simultaneous masks replaced all of the characters in the masking region after the delay period. The sequential masks replaced only some of the characters after an initial delay, but then continued to mask the remaining characters in the region after additional delay periods.

For the 7-character masking region, there were two simultaneous mask conditions: A 30-msec delayed mask and a 50-msec delayed mask. For these conditions, the entire line of text was visible at the start of each fixation. After the delay period (e.g., $30 \mathrm{msec}$ from the start of fixation in one condition), the 7-character region surrounding the fixated character was masked for the rest of the fixation. For the 15-character masking region, the simultaneous masks were presented after a 50-msec or a 90 -msec delay.

A sequential 7-character mask is depicted in Figure 1. Imagine that the subject was fixated on the first letter $A$ in MAGAZINE just above the dot. The masked region included three letter spaces to the left and to the right of the fixated letter. These are the characters $E M A G A Z$. After $30 \mathrm{msec}$, the mask replaced the letters $M A G$ as depicted by the $\mathrm{Xs}$ in Figure 1. After an additional $10 \mathrm{msec}$, the space after THE and the $A$ were masked, and finally, the $E$ in THE and the $Z$ in MAGAZINE were masked after another $10 \mathrm{msec}$, to complete the 7-character region. Thus, $50 \mathrm{msec}$ after the beginning of the fixation, the entire 7-character area was masked. In another sequential condition the mask first replaced the outermost letters in the 7-character region $(E$ and $Z)$ at a 30 -msec delay period. After an additional $10 \mathrm{msec}$, the space and the $A$ were 
7 CHAR SEQUENTIAL MASK - $30,40,50$

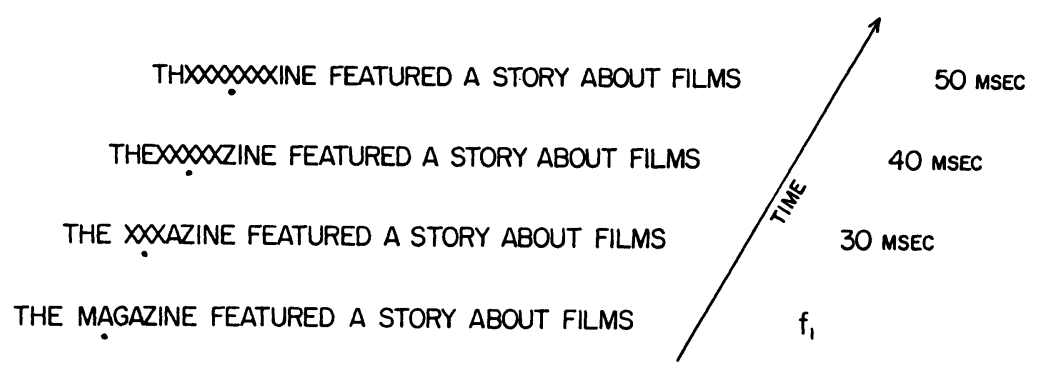

Figure 1. A 7-character mask with sequential onset after 30-, 40-, and 50-msec delays. The dot marks the fixated character.

replaced by a mask, and, after another $10 \mathrm{msec}$, the central 3 letters $(M A G)$ were masked. This sequential mask also resulted in a 7-character masked area after $50 \mathrm{msec}$ from the beginning of the fixation. In one case the mask grew from the center of fixation outward, and in the other it grew from the outside inward. These masking conditions will be referred to by the amount of time that the letters were exposed. The 30-40-50 sequential mask refers to the condition that masked the fixated letters first. The 50-40-30 sequential mask refers to the condition that masked the outside letters first.

In the sequential 15-character mask condition, the masked region included 7 letters to the left and right of fixation. These are the letters $M A G A Z I N E$ FEATUR with the subject fixated on the letter $E$ in $M A G A$ ZINE. The letters ZINE FE were masked after $50 \mathrm{msec}$. After an additional $20 \mathrm{msec}, 2$ more letters were masked on either side to include GAZINE FEAT. After another $20 \mathrm{msec}, 2$ more letters were masked on either side to include MAGAZINE FEATUR. Thus, after a $90-\mathrm{msec}$ delay, the entire 15-character region was masked. This condition will be referred to as the 50-70-90 mask condition. The 17-character region was also masked from the outside inward (the 90-70-50 condition). In the no-mask condition, the sentences were displayed normally without any mask throughout the fixation.

The four delay conditions and two mask sizes resulted in eight experimental conditions. Each subject read 8 sentences in each condition plus 8 sentences in the no-mask condition. The sentences were balanced so that each subject received a different set of sentences in each condition, and the order of experimental conditions was rotated over subjects. Subjects read 16 practice sentences at the beginning of the experiment.

\section{Results and Discussion}

Analyses of variance were carried out on reading rate, total number of fixations, fixation duration, and saccade length (see Table 1). The effect of the masking conditions on reading rate was significant $[F(8,64)=12.1$, $p<.001]$. A Neuman-Keuls test showed that reading rate was significantly slower for the 7-character simultaneous mask at $30 \mathrm{msec}$ and the 7-character sequential mask at 50-40-30 msec than for all of the other conditions $(p<.05)$, but that these two conditions did not differ from each other. Although the 7-character sequential mask at 30-40-50-msec delay allowed some of the letters to be presented for only $30 \mathrm{msec}$, reading rate in this condition was no worse than in the 50 -msec simultaneous mask condition. However, reading performance in both the 30 msec delay condition and the condition that presented the more parafoveal characters $(50-40-30)$ for only $30 \mathrm{msec}$ was poorer than in the 50 -msec simultaneous mask condition. Also, the other sequential mask, which presented the more parafoveal characters for only $30 \mathrm{msec}$, was more difficult. These results suggest that the characters that are closest to the point of fixation can be processed more quickly, or require less visual information during the fixation, than the other characters farther from the fixation point. Reading rates did not differ among the other long delays in the 15-character mask conditions. Reading rate was faster for the no-mask condition than for the other conditions.

Analyses of the other measures showed that the differences were primarily due to the number of fixations in a given condition $[F(8,64)=11.15, p<.001]$. A Neuman-Keuls test showed more fixations in the 7character mask at 30-msec delay and the 7-character mask at 50-40-30-msec delay than in any of the other conditions $(p<.05)$. These two conditions did not differ from each other. Although there was a significant difference in fixation duration $[F(8,64)=5.64, p<.001]$, it was entirely due to shorter fixations in the no-mask condition $(p<.05)$. There were no differences in saccade length $(F<1)$.

Table 1

Means for the Dependent Variables in Experiments 1 and 2

\begin{tabular}{|c|c|c|c|c|}
\hline & $\begin{array}{l}\text { Reading } \\
\text { Rate }\end{array}$ & $\begin{array}{l}\text { Fixation } \\
\text { Duration }\end{array}$ & $\begin{array}{l}\text { Number of } \\
\text { Fixations }\end{array}$ & $\begin{array}{l}\text { Saccade } \\
\text { Length }\end{array}$ \\
\hline \multicolumn{5}{|c|}{$\begin{array}{l}\text { EXPERIMENT 1 } \\
\text { elayed 7-Character Mz }\end{array}$} \\
\hline $\begin{array}{c}30 \\
30-40-50 \\
50 \\
50-40-30\end{array}$ & $\begin{array}{l}223 \\
281 \\
279 \\
238\end{array}$ & $\begin{array}{l}253 \\
240 \\
245 \\
249\end{array}$ & $\begin{array}{l}6.8 \\
5.5 \\
5.6 \\
6.2\end{array}$ & $\begin{array}{l}6.8 \\
7.2 \\
7.3 \\
7.1\end{array}$ \\
\hline \multicolumn{5}{|c|}{ Delayed 15-Character Mask } \\
\hline $\begin{array}{c}50 \\
50-70-90 \\
90 \\
90-70-50 \\
\text { No Mask }\end{array}$ & $\begin{array}{l}289 \\
280 \\
306 \\
293 \\
346\end{array}$ & $\begin{array}{l}252 \\
248 \\
236 \\
244 \\
212\end{array}$ & $\begin{array}{l}5.4 \\
5.5 \\
5.1 \\
5.2 \\
5.0\end{array}$ & $\begin{array}{l}7.6 \\
7.2 \\
7.1 \\
7.3 \\
7.5\end{array}$ \\
\hline \multicolumn{5}{|c|}{$\begin{array}{c}\text { EXPERIMENT 2 } \\
\text { 7-Character Masks/Window }\end{array}$} \\
\hline $\begin{array}{c}30 \\
50 \\
30-40-50 \\
50-60-70 \\
\text { No Mask }\end{array}$ & $\begin{array}{l}122 \\
149 \\
130 \\
156 \\
200\end{array}$ & $\begin{array}{l}280 \\
257 \\
269 \\
253 \\
218\end{array}$ & $\begin{array}{r}11.9 \\
10.6 \\
11.6 \\
10.2 \\
9.3\end{array}$ & $\begin{array}{l}4.1 \\
4.4 \\
4.2 \\
4.7 \\
4.8\end{array}$ \\
\hline
\end{tabular}

Note-Reading rate is given in words per minute; fixation duration is given in milliseconds; and saccade length is given in characters. 
As indicated, with 15-character masks, there were no differences between conditions. The longer delays used were apparently sufficiently long that most of the useful visual information could be acquired prior to the onset of the mask. There was, however, a 50-word-per-minute difference between the no-mask condition and the 15character mask conditions. This difference is larger than that found previously by Rayner et al. (1981), but their subjects were considerably more practiced in the task than those used here.

It should be noted that we masked the fixated letter and the 3 characters to the right of fixation (in the 7-character condition) in a sequential left-to-right manner. However, the 3 characters to the left of fixation were also masked sequentially (from right to left). The same point also applies to the 15-character mask. In a sense, then, our experimental manipulation is a comparison of an inside-out and an outside-in mask. In the case of the 15-character mask, there was no difference between the inside-out and outside-in masks. As noted above, apparently the time frames for the masks' onsets were sufficiently long that most of the useful information was acquired prior to the mask onset, and perhaps the poorer performance in comparison to the control condition was due to a general disturbance effect related to the mask onset. In the case of the 7-character mask, performance was significantly poorer in the outside-in than in the inside-out condition. An explanation for the difference is that letters are processed serially in the center of vision, and, although there was sufficient time to process the centermost letter prior to mask onset, there was not sufficient time to process the more parafoveal letters. Given that there is evidence that attention is directed to the right of fixation reading (Rayner, Well, \& Pollatsek, 1980), the data are consistent with a left-to-right sequential scan of the letters in the center of vision. However, there is an alternative explanation that has not been ruled out by this experiment. Possibly, the letters that are fixated are partially identified from parafoveal vision during the previous fixation (Rayner, Well, Pollatsek, \& Bertera, 1982). If some visual information is accumulated on the previous fixation, it could facilitate identification of the letters when they are fixated. In order to test this hypothesis, we re- moved parafoveal information during the previous fixation by presenting the delayed mask within a window surrounded by a mask in Experiment 2 .

\section{EXPERIMENT 2}

In Experiment 2, all reading was done with a moving window (McConkie \& Rayner, 1975; Rayner et al., 1981; Rayner et al., 1982), which prevented the reader from seeing letters beyond the specified number exposed for a given window size. When the 7-character sequential mask at 30-40-50-msec delay is presented in a 7-character window, none of the characters beyond the 7-character region are visible. If parafoveal processing caused performance to be better in this condition than in the 7character simultaneous mask at 30-msec in Experiment 1, then this advantage should disappear in Experiment 2, since parafoveal processing is obstructed by the window (see Figure 2).

\section{Method}

Subjects. Ten volunteers with normal uncorrected vision were paid to serve as subjects.

Design. Four 7-character masking conditions were used. Two conditions used simultaneous masks at 30-msec and 50-msec delays. The other two conditions used sequential masks similar to those used in Experiment 1 . The sequential masks were presented with a 30-40-50-msec delay and a 50-60-70-msec delay. This second sequential mask was included to ensure that there was no interference peculiar to the presentation of a mask in sequence. A no-mask control condition was also included in which the entire 7-character region was visible throughout the fixation. Each of these conditions was presented within a 7-character window. At the beginning of each fixation, only the 7 characters around the center of fixation were exposed. These 7 characters were masked after the delay period so that once the mask was presented, the entire line of text was masked.

Each condition consisted of 16 sentences. The sentences were balanced so that each subject received a different set of sentences in each condition, and the order of experimental conditions was rotated over subjects. Subjects read 16 practice sentences at the beginning of the experiment.

\section{Results and Discussion}

The effect of the masking conditions on reading rate (see Table 1) was significant $[F(4,36)=31.0, p<.001]$. A Neuman-Keuls test indicated that reading rates in both

7 CHAR WINDOW WITH DELAYED SEQUENTIAL MASK

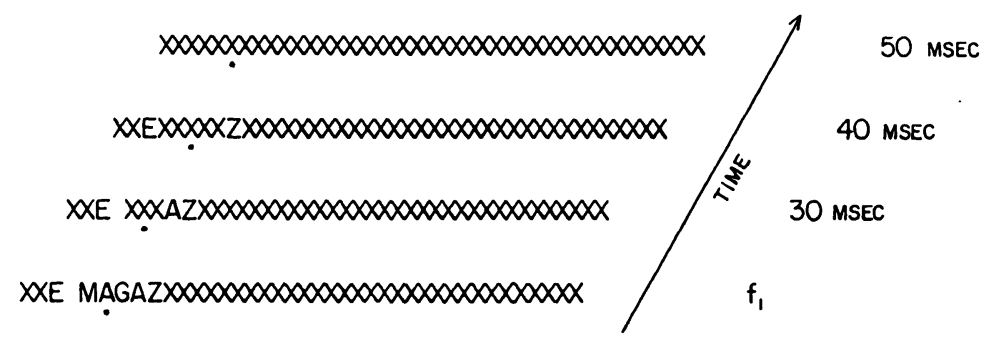

Figure 2. A 7-character mask with sequential onset embedded in a moving window. The dot marks the fixated character. 
the 30-msec delay and the 30-40-50-msec delay conditions were worse than those in the 50-msec delay and the $50-60-70-$ msec delay conditions $(p<.05)$, but they were not different from each other. This suggests that the advantage in processing the center 3 characters in Experiment 1 was due to some information obtained from the parafovea on the previous fixation. Reading rate in the no-mask condition was better than in all other conditions.

Analyses of the other measures (see Table 1) indicated that the masking conditions affected the number of fixations $[F(4,36)=9.9, p<.01]$, fixation duration $[F(4,36)$ $=34, p<.001]$, and saccade length $[F(4,36)=4.5$, $p<.01]$. There were more fixations in the 30 -msec delay mask and the 30-40-50-msec delay than in the other conditions. There were also more fixations in the 50-msec delay condition than in the no-mask condition. Fixation durations were shorter in the no-mask condition than in any of the other conditions, and longer in the $30-\mathrm{msec}$ delay and the 30-40-50-msec delay than in the other conditions. Saccade length was shorter in the 30-msec delay and the 30-40-50-msec delay, but not significantly different from that in the 50-msec delay condition.

The results of Experiment 2 are inconsistent with the serial model. We eliminated the possibility of preliminary processing of parafoveal information by presenting the text only in a small region around the fixation point. The serial model predicts that the superior performance obtained in the 30-40-50-mask condition (with respect to the 30-msec delayed mask) in Experiment 1 should hold in Experiment 2. However, in Experiment 2 there was no difference between these two critical conditions and they both resulted in slower reading rates than did the 50msec delay condition. As in Experiment 1, performance in the 50-msec delay condition was significantly different from that in the control condition. The fact that subjects in the current experiments had considerably less prac- tice in the tasks than did subjects in the Rayner et al. (1981) study may explain the difference in results.

In summary, the results of Experiments 1 and 2 taken together are inconsistent with a serial letter processing model during reading. In Experiment 1, we did obtain results consistent with a serial scan and input rate of $10 \mathrm{msec}$ per letter during an eye fixation, as proposed by Geyer (1970). However, in Experiment 2 when readers did not have an opportunity to do any prior processing of parafoveal letters, we found significant differences in reading rates between the condition in which the entire 7-character region was masked after 50-msec and the condition in which the central characters were masked sequentially. Thus we conclude that the advantage that the central characters seem to have derives from prior processing when those letters are in parafoveal vision and not from a sequential letter scan.

\section{REFERENCES}

GEYER, J. J. (1970). Models of perceptual processes in reading. In H. Singer \& R. B. Ruddell (Eds.), Theoretical models and processes of reading. Newark, DE: International Reading Association.

McConKIE, G. W., \& RAYNER, K. (1975). The span of the effective stimulus during a fixation in reading. Perception \& Psychophysics, 17, 578-586.

RAYNer, K., INHOFF, A. W., Morrison, R. E., SLOWIACZeK, M. L., \& BERTERA, J. H. (1981). Masking of foveal and parafoveal vision during eye fixations in reading. Journal of Experimental Psychology: Human Perception \& Performance, 7, 167-179.

Rayner, K., Well, A. D., \& Pollatsek, A. (1980). Asymmetry of the effective visual field in reading. Perception \& Psychophysics, 27, 537-544.

Rayner, K., Well, A. D., Pollatsek, A., \& Bertera, J. H. (1982). The availability of useful information to the right of fixation in reading. Perception \& Psychophysics, 31, 537-550.

(Manuscript received for publication December 8, 1986.) 